\title{
Penyerapan Karbondioksida Oleh Kolom Molecular Sieve Pada Sistem Pemurnian Helium Dalam Peluit
}

\author{
Sriyono ${ }^{1 *}$, Rahayu Kusumastuti', Djati H. Salimy ${ }^{1}$, Ign. Djoko Irianto', Sofia L. Butar Butar, A. \\ Hafid $^{1}$, M. Subekti ${ }^{1}$, Topan Setiadipura ${ }^{1}$, Geni Rina Sunaryo' \\ ${ }^{1}$ Pusat Teknologi dan Keselamatan Reaktor Nuklir (PTKRN)-BATAN, Gedung 80, Kawasan Puspiptek, Serpong, Tangerang \\ Selatan, Indonesia
}

\begin{abstract}
INFORMASI ARTIKEL
Riwayat Artikel:

Diterima:

03 Februari 2021

Diterima dalam bentuk revisi: 06 Mei 2021

Disetujui:

10 Mei 2021

Kata kunci:

Penyerapan

Karbondioksida

Molecular sieve

Pemurnian

Helium

Peluit

ABSTRAK

PENYERAPAN KARBONDIOKSIDA OLEH KOLOM MOLECULAR SIEVE PADA SISTEM PEMURNIAN HELIUM DALAM PELUIT. Peluit adalah desain konseptual reaktor daya yang dirancang berdasar teknologi High Temperature Gas-cooled Reactor (HTGR), dengan siklus konversi daya tidak langsung. Pendingin primer Peluit adalah gas helium dan harus dijaga kemurniannya dari pengotor $\mathrm{CO}_{2}$ dibawah 0,6 parts per million by volume (ppmv) berdasarkan persyaratannya. $\mathrm{CO}_{2}$ terbentuk karena reaksi oksigen atau air dengan karbon di teras pada saat kejadian water/air ingress. Dampak $\mathrm{CO}_{2}$ terhadap sistem, struktur dan komponen (SSK) adalah terjadinya reaksi dekarburisasi pada tabung steam generator. Dalam sistem pemurnian helium Peluit, komponen penyerap $\mathrm{CO}_{2}$ adalah kolom molecular sieve jenis $5 \mathrm{~A}$. Penelitian ini bertujuan mendemonstrasikan simulasi proses penyerapan pengotor $\mathrm{CO}_{2}$ pada kolom molecular sieve sepanjang ketinggian kolom yang dirancang sehingga hasil penyerapan menghasilkan konsentrasi batas maksimal pada pendingin primer tidak terlampaui. Metodologi yang digunakan adalah pemodelan perhitungan dengan software Matlab dengan metode penyerapan adalah metode Henry. Tinggi kolom diasumsikan $200 \mathrm{~cm}$, diameter kolom $50 \mathrm{~cm}$, laju aliran gas helium adalah $5 \%$ dari aliran utama pendingin primer setara dengan $3,0 \mathrm{~kg} / \mathrm{s}$, dan konsentrasi pengotor $\mathrm{CO}_{2}$ adalah 40 ppmv. Berdasarkan simulasi diketahui bahwa setelah 5 detik, gas helium bersih sudah keluar dari ujung kolom dengan konsentrasi pengotor $\mathrm{CO}_{2}$ tersisa $4 \times 10^{-5}$ ppmv. Dengan hasil ini menunjukkan bahwa kolom molecular sieve mampu membersihkan pengotor $\mathrm{CO}_{2}$ dengan efisiensi $99,99 \%$ dan dapat disimpulkan bahwa molecular sieve tipe $5 \mathrm{~A}$ cocok digunakan pada sistem pemurnian helium Peluit.
\end{abstract}

\begin{abstract}
CARBON DIOXIDE ADSORPTION AT MOLECULAR SIEVE BED OF HELIUM PURIFICATION SYSTEM IN THE PELUIT. The Peluit is a conceptual design of a power reactor based on High Temperature Gas-cooled Reactor (HTGR) with indirect power conversion. The primary coolant of Peluit is helium and its purity must be maintained from $\mathrm{CO}_{2}$ below 0.6 parts per million by volume (ppmv) by its requirements. $\mathrm{CO}_{2}$ is formed due to the reaction of oxygen or water with a carbon in the core during the water/air ingress. The impact of $\mathrm{CO}_{2}$ to systems, structures and components (SSC) is steam generator tubes decarburization. In the helium purification system (HPS) of Peluit, the $\mathrm{CO}_{2}$ removal component is a $5 \mathrm{~A}$ type molecular sieve bed. This research aims to demonstrate the simulation of $\mathrm{CO}_{2}$ adsorption in the molecular sieve bed along its design to achieve below its requirement limits. The Matlab software is used to simulate the adsorption process with the Henry method. The height of the column bed is assumed to be $200 \mathrm{~cm}$, the diameter of the column is 50 $\mathrm{cm}$, the flow rate of helium gas is $5 \%$ of the main primary coolant mass flow rate equivalent to 3.0 $\mathrm{kg} / \mathrm{s}$, and the concentration of $\mathrm{CO}_{2}$ is $40 \mathrm{ppmv}$. Based on the simulation it is known that after 5 seconds, the pure helium has come out at the end of the column with the remaining $\mathrm{CO}_{2}$ concentration of $4.0 \times 10^{-5} \mathrm{ppmv}$. These results indicate that the molecular sieve bed is capable of removing $\mathrm{CO}_{2}$ with an efficiency of $99.99 \%$ and it concluded that molecular sieve $5 \mathrm{~A}$ suitable for helium purification of Peluit.

Keywords: adsorption, carbon dioxide, molecular sieve, purification, helium, Peluit.
\end{abstract}

\section{PENDAHULUAN}

Indonesia memiliki banyak penduduk dan membutuhkan pasokan energi yang besar. Untuk mendorong peningkatan ekonomi masyarakat, selain energi listrik, dibutuhkan pula energi panas yang dapat digunakan untuk mengolah sumber daya alam mentah menjadi produk yang lebih bernilai ekonomis [1]. Pada Tahun 2019, Batan bekerjasama dengan Tsing Hua University China membuat desain konseptual reaktor daya yang dinamakan 
Pembangkit Uap Untuk Industri (Peluit). Peluit didesain berdasarkan teknologi pebble reactor [2]. Peluit berdaya 150 MW thermal, bersifat modular, mempunyai keselamatan pasif [3], dan mampu untuk kogenerasi [4]. Reaktor ini didesain dengan siklus konversi daya tak langsung (indirect cycle), dengan gas helium sebagai pendingin primer sedangkan air sebagai pendingin sekunder. Peluit menggunakan bahan bakar bola (pebble), dengan skema pengisian bahan bakar multipass [2] .

Pendingin primer helium adalah salah satu sistem yang sangat penting dalam Peluit. Kemurnian helium pada sistem primer harus dijaga dari berbagai gas pengotor $\mathrm{CO}, \mathrm{CH}_{4}, \mathrm{CO}_{2}$, $\mathrm{H}_{2}, \mathrm{H}_{2} \mathrm{O}, \mathrm{O}_{2}, \mathrm{~N}_{2}$ dan gas-gas mulia produk fisi agar dampak buruk terhadap pekerja dan sistem, struktur \& komponen (SSK) dapat dicegah [5]. Dampak buruk tersebut adalah reaksi oksidasi grafit, deposisi karbon, dekarburisasi, dan peningkatan paparan radiasi pada SSK [6][7]. Timbulnya pengotor pada pendingin primer diakibatkan adanya reaksi antara air atau udara yang masuk ke teras dengan material SSK primer yang mayoritas terbuat dari bahan karbon, seperti bahan bakar pebble, reflektor dan absorber pebble [8].

Desain konseptual Sistem Pemurnian Helium (SPH) pada Peluit dirancang dengan 3 buah rangkaian (train), 2 train dioperasikan pada saat operasi normal secara bergantian atau redundancy, sedangkan 1 train dioperasikan pada saat kondisi kecelakaan (accident). Pengotor pada pendingin primer Peluit dikategorikan menjadi 2 macam yaitu pengotor partikel padat (particulate impurities) dan pengotor gas (gaseous impurities) [9][10]. Selama reaktor beroperasi gas-gas pengotor akan terbentuk dan SPH dirancang untuk memisahkan berbagai pengotor agar kualitas helium selalu terjaga dengan konsentrasi pengotor selalu dibawah batas yang dipersyaratkan [3], [11]. Beberapa tahapan pada proses pemisahan pengotor yaitu penyaringan debu karbon, oksidasi dengan oksidator $\mathrm{CuO}$, kondensasi air, adsorpsi atau penyaringan molekuler, dan adsorpsi karbon aktif pada kondisi temperatur kriogenik [12]. Filtrasi debu karbon dilakukan dengan cartridge filter HEPA [9]. Proses oksidasi berfungsi mengkonversi $\mathrm{CO}$ menjadi $\mathrm{CO}_{2}$ dan $\mathrm{H}_{2}$ menjadi $\mathrm{H}_{2} \mathrm{O}$ dengan oksidator $\mathrm{CuO}$ [13]. Air atau $\mathrm{H}_{2} \mathrm{O}$ yang terbentuk dikondensasi dengan water trap, sedangkan $\mathrm{CO}_{2}$ ditangkap dengan molecular sieve. Oksigen $\left(\mathrm{O}_{2}\right)$, nitrogen $\left(\mathrm{N}_{2}\right)$ dan gas-gas mulia produk fisi (Xe, $\mathrm{Kr}$ ) [14] dihilangkan dengan penyerap karbon pada kondisi temperatur kriogenik [15].

Gas $\mathrm{CO}_{2}$ yang terkandung dalam pendingin helium dapat mempengaruhi penurunan kekuatan mekanik tabung steam generator yang disebabkan oleh proses dekarburisasi suhu tinggi [16]. Dengan adanya deposisi karbon pada permukaan tabung juga akan mengakibatkan penurunan efisiensi perpindahan panasnya [17]. Kerusakankerusakan tersebut akan memperpendek usia komponen [16]. Pengendalian kimia pada pendingin primer ataupun sekunder reaktor Peluit harus dilakukan secara ketat agar keandalan SSK terjamin. Selain mencegah adanya korosi grafit di teras reaktor, pengendalian berbagai pengotor pada pendingin primer juga akan mempertahankan keandalan dan kekuatan SSK [18].

Salah satu komponen utama SPH adalah kolom/bed molecular sieve. Kolom ini berfungsi menyerap gas $\mathrm{CO}_{2}$. Proses penyerapan gas $\mathrm{CO}_{2}$ pada molecular sieve menggunakan prinsip pressure swing adsorption (PSA). Hasil penelitian sebelumnya telah diketahui bahwa tekanan optimum untuk proses PSA pada kolom molecular sieve adalah 30 bar [7]. Sedangkan temperatur optimalnya adalah temperatur kamar, $30{ }^{\circ} \mathrm{C}$. Pada perancangan kolom molecular sieve, faktor ketinggian kolom menjadi hal yang sangat penting. Semakin tinggi kolom efisiensi pemisahan semakin baik, karena interaksi gas helium dengan molecular sieve semakin lama, sehingga gas helium dengan kemurnian tinggi akan didapatkan. Akan tetapi secara ekonomi, kolom molecular sieve yang tinggi tidak menguntungkan. Oleh sebab itu pada penelitian ini akan dilakukan pemodelan dan simulasi proses penyerapan pada kolom molecular sieve secara pressure swing adsorption (PSA) dengan metode Henry [19]. Molecular sieve yang digunakan adalah tipe 5A. Tujuan simulasi adalah untuk mendapatkan hasil pemurnian gas helium dari pengotor gas $\mathrm{CO}_{2}$ pada berbagai variasi ketinggian kolom. Metodologi yang digunakan adalah perhitungan dan pemodelan kolom molecular sieve dengan perangkat lunak Matlab. Rancangan ketinggian kolom sangat 
menentukan waktu kontak gas helium kotor dengan molecular sieve. Dengan mengetahui karakteristik proses penyerapan pada berbagai ketinggian kolom dapat ditentukan rancangan tinggi optimum kolom sehingga secara ekonomi lebih menguntungkan.

\section{TEORI}

\subsection{Sistem Pemurnian Helium Reaktor Peluit}

Desain konseptual Sistem Pemurnian Helium (SPH) pada Peluit dirancang dengan 3 buah rangkaian (train), 2 train dioperasikan pada saat operasi normal, sedangkan 1 train dioperasikan pada saat kondisi kecelakaan (accident). Dua train memiliki 5 komponen utama seperti ditunjukkan pada Gambar 1. Spesifikasi teknis pendingin primer dan sekunder Peluit ditunjukkan pada Tabel 1.

Tabel 1. Spesifikasi Teknis Pendingin Peluit.

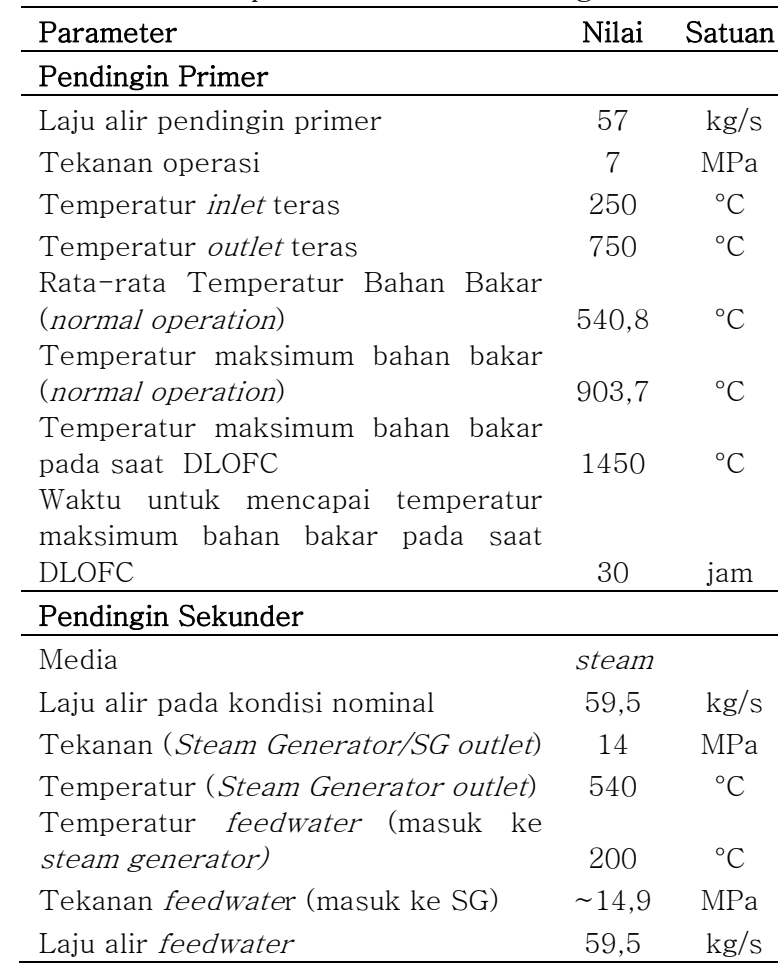

Komponen-komponen utama tersebut adalah cartridge filter, bed oksidator $\mathrm{CuO}$, condenser/cooler, bed molecular sieve, dan bed karbon aktif kondisi kriogenik. Setiap komponen mempunyai fungsi membersihkan pengotor yang spesifik sesuai dengan kapasitasnya. Cartridge filter HEPA membersihkan debu karbon, bed oksidator $\mathrm{CuO}$ mengkonversi $\mathrm{H}_{2}$ menjadi $\mathrm{H}_{2} \mathrm{O}$ dan $\mathrm{CO}$ menjadi $\mathrm{CO}_{2}$, condenser memisahkan air dari pendingin helium, bed molecular sieve menyerap $\mathrm{CO}_{2}$ dan $\mathrm{CH}_{4}$, sedangkan karbon aktif menyerap oksigen dan nitrogen yang beroperasi pada kondisi kriogenik [20].

Aliran pendingin primer Peluit adalah 57 $\mathrm{kg} /$ detik, sedangkan aliran masuk ke $\mathrm{SPH}$ didesain 5\% dari aliran utama yaitu 3,0 $\mathrm{kg} /$ detik.

\subsection{Interaksi Udara dan Air Terhadap Material Karbon di Teras Peluit}

Udara dan air yang masuk ke pendingin primer Peluit terbawa oleh aliran sehingga di dalam teras akan berinteraksi dengan material teras reaktor yang sebagian besar terbuat dari material karbon (seperti bahan bakar, reflector, absorber ball, dll.). Air dan udara dapat masuk ke pendingin primer dimunngkinkan pada saat kejadian water/air ingress [21]. Water ingress terjadi ketika ada kebocoran (leakage) sisi pendingin primer yang masuk ke pendingin primer. Kebocoran terjadi akibat kerusakan tabung-tabung steam generator [18], [21], [22]. Sedangkan udara masuk ke pendingin primer dimungkinkan pada saat perawatan tahunan [23], [24]. Reaksi-reaksi yang mungkin terjadi ditunjukkan pada persamaanpersamaan (1-8) dibawah ini[9].

$$
\begin{aligned}
& \mathrm{C}+\mathrm{H}_{2} \mathrm{O} \rightarrow \mathrm{CO}+\mathrm{H}_{2} \\
& \mathrm{C}+\mathrm{CO}_{2} \rightarrow 2 \mathrm{CO} \\
& \mathrm{H}_{2} \mathrm{O} \rightarrow \frac{1}{2} \mathrm{O}_{2} \\
& \mathrm{C}+\frac{1}{2} \mathrm{O} \rightarrow \mathrm{CO} \\
& \mathrm{C}+\mathrm{O}_{2} \rightarrow \mathrm{CO}_{2} \\
& \mathrm{CO}+\frac{1}{2} \mathrm{O}_{2} \rightarrow \mathrm{CO}_{2} \\
& \mathrm{C}+2 \mathrm{H}_{2} \rightarrow \mathrm{CH}_{4} \\
& \mathrm{CO}+\mathrm{H}_{2} \mathrm{O} \rightarrow \mathrm{CO}_{2}+\mathrm{H}_{2}
\end{aligned}
$$

Dari keseluruhan reaksi di atas, diketahui bahwa di aliran pendingin helium akan terbentuk pengotor antara lain $\mathrm{CO}, \mathrm{CH}_{4}, \mathrm{CO}_{2}$, $\mathrm{H}_{2}, \mathrm{H}_{2} \mathrm{O}$, dan $\mathrm{O}_{2}$ [16]. Sedangkan pengotor $\mathrm{N}_{2}$ timbul karena adanya udara yang masuk ke pendingin primer, dan secara alamiah udara telah mengandung $\mathrm{N}_{2}$ [25]. 


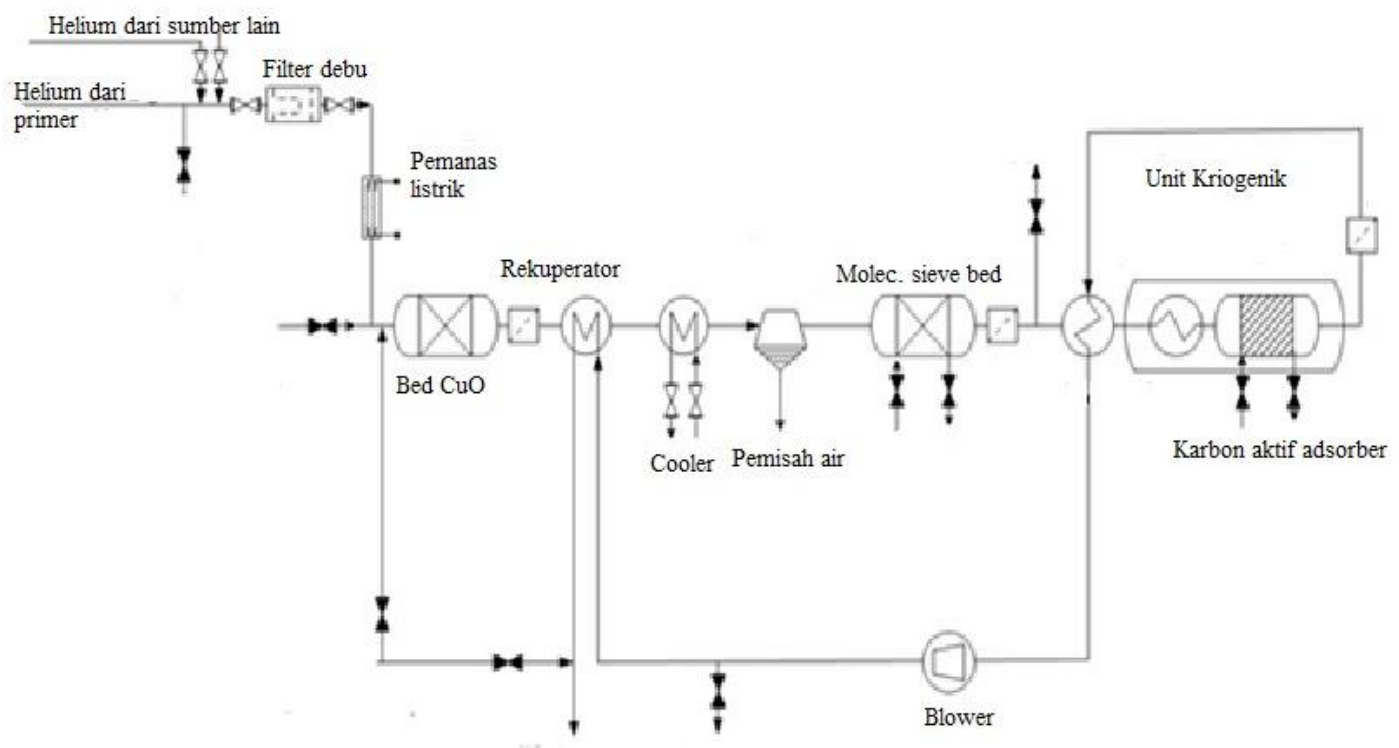

Gambar 1. Komponen utama satu buah rangkaian (train) Sistem Pemurnian Helium Peluit..

Batasan konsentrasi pengotor di dalam pendingin primer Peluit telah ditetapkan dan mengadopsi pada desain RDE [26] dan HTR-10 China [27] ditunjukkan pada Tabel 2.

Tabel 2. Konsentrasi pengotor yang diijinkan di dalam pendingin primer Peluit.

\begin{tabular}{cc}
\hline \multicolumn{2}{c}{ pendingin primer Peluit. } \\
\hline Pengotor & $\begin{array}{c}\text { Batas maksimum } \\
(\text { ppmv })\end{array}$ \\
\hline $\mathrm{H}_{2} \mathrm{O}$ & $\leq 0,2$ \\
$\mathrm{O}_{2}$ & $\leq 0,02$ \\
$\mathrm{~N}_{2}$ & $\leq 1,0$ \\
$\mathrm{CO}_{2}$ & $\leq 0,6$ \\
$\mathrm{CO}$ & $\leq 3,0$ \\
$\mathrm{CH}_{4}$ & $\leq 1,0$ \\
$\mathrm{H}_{2}$ & $\leq 5,0$ \\
\hline
\end{tabular}

*ppmv $=$ part per millions by volume

Karena pengotor gas $\mathrm{H}_{2}$ dan $\mathrm{CO}$ sulit untuk diserap maka kedua gas ini harus dikonversi terlebih dahulu menjadi $\mathrm{H}_{2} \mathrm{O}$ dan $\mathrm{CO}_{2}$ yang mempunyai ukuran molekul lebih besar sehingga mudah dipisahkan. Gas $\mathrm{H}_{2}$ dan $\mathrm{CO}$ dikonversi menjadi $\mathrm{H}_{2} \mathrm{O}$ dan $\mathrm{CO}_{2}$ dengan menggunakan oksidator $\mathrm{CuO}$ (reaktor $\mathrm{CuO}$ ) pada temperatur $350^{\circ} \mathrm{C}$ [28]-[31]. Reaksi konversi ditunjukkan pada persamaan (9), (10) dan (11). Dalam proses ini $\mathrm{CH}_{4}$ juga akan mengalami oksidasi menghasilkan $\mathrm{H}_{2} \mathrm{O}$ dan $\mathrm{CO}_{2}$.

$\mathrm{H}_{2}+\mathrm{CuO} \rightarrow \mathrm{H}_{2} \mathrm{O}+\mathrm{Cu}$

$\mathrm{CO}+\mathrm{CuO} \rightarrow \mathrm{CO}_{2}+\mathrm{Cu}$

$\mathrm{CH}_{4}+4 \mathrm{CuO} \rightarrow 2 \mathrm{H}_{2} \mathrm{O}+\mathrm{CO}_{2}+4 \mathrm{Cu}$

Dengan demikian maka seluruh senyawa yang sulit untuk diserap dapat dihilangkan. Jika oksidator jenuh maka dilakukan regenerasi menggunakan Oksigen pada suhu $300{ }^{\circ} \mathrm{C}$. Setelah proses koversi gas $\mathrm{H}_{2}$ dan $\mathrm{CO}$ menjadi $\mathrm{H}_{2} \mathrm{O}$ dan $\mathrm{CO}_{2}$ dilakukan maka selanjutnya gas helium pendingin primer dilewatkan melalui kolom penyaring molekuler (molecular sieve) yang beroperasi pada temperatur kamar $\left(30^{\circ} \mathrm{C}\right)$ dan tekanan tertentu. Pada kolom ini akan terjadi adsorpsi gas $\mathrm{CO}_{2}$, dan $\mathrm{H}_{2} \mathrm{O}$.

\subsection{Proses Adsorpsi pada Molecular Sieve}

Proses pemisahan antara adsorbat dalam media tertentu oleh zat padat (adsorben) disebut dengan adsorpsi. Adsorbat akan terikat pada permukaan adsorben, jumlah atau besarnya adsorbat yang terserap ditentukan oleh daya adsorpsi suatu adsorben. Proses adsorpsi tergantung pada konsentrasi keseimbangan zat terlarut atau tekanan adsorpsi gas, temperatur proses, luas spesifik padatan atau luas permukaan adsorben, dan sifat adsorbat/adsorben itu sendiri [30], [32]. Makin kecil ukuran butir adsorben maka makin besar pula luas permukaannya, sehingga daya adsorpsi semakin kuat. Sifat adsorpsi pada permukaan zat padat sangat selektif artinya pada campuran zat hanya satu komponen yang diadsorpsi oleh zat padat tertentu. Metode yang digunakan pada proses adsorpsi ada beberapa antara lain : metode Langmuir, metode Henry, dan metode Freundlich.

Metode adsorpsi Langmuir pada kondisi isotermal didasarkan atas beberapa asumsi, yaitu (a) adsorpsi hanya terjadi pada lapisan 
tunggal (monolayer), (b) panas adsorpsi tidak tergantung pada penutupan permukaan, dan (c) seluruh permukaan adsorben bersifat homogen. Jenis molecular sieve sangat bermacammacam, penggunaannya sangat tergantung pada jenis pengotor yang akan dibersihkan. Untuk pengotor $\mathrm{CO}_{2}$ jenis yang digunakan adalah tipe 5A. Spesifikasi teknis molecular sieve 5A ditunjukkan pada Tabel 3.

\begin{tabular}{cc} 
Tabel 3. Spesifikasi molecular sieve tipe 5A. [33] \\
\hline Parameter & Nilai \\
\hline Luas permukaan per gram & $700 \mathrm{~s} / \mathrm{d} 800 \mathrm{~m}^{2}$ \\
Diameter pori & $5 \AA$ \\
Porositas internal & 0,7 \\
Volume pori per gram & $0,3 \mathrm{~cm}^{3}$ \\
Ukuran partikel & $1,6 \mathrm{~mm}$ \\
\hline
\end{tabular}

\section{METODOLOGI}

Proses adsorpsi pada kolom molecular sieve dimodelkan dan disimulasi menggunakan software Matlab. Penyerapan gas pengotor $\mathrm{CO}_{2}$ pada molecular sieve bekerja berdasarkan prinsip Pressure Swing Adsorption (PSA). PSA adalah proses adsorpsi berdasarkan pada kecenderungan gas untuk tertangkap pada tekanan tinggi dan terdesorpsi (terlepas kembali) pada tekanan yang lebih rendah. Proses PSA berguna untuk memurnikan produk yang diinginkan hingga tingkat yang sangat kecil bergantung dengan adsorben (bahan penyerap) yang digunakan. Adsorben yang digunakan untuk PSA sangat tergantung dengan jenis dan konsentrasi pengotor yang ingin dibersihkan. Pada perhitungan ini, ditentukan tinggi kolom, diameter kolom, porositas adsorben, dan konsentrasi awal pengotor. Ketinggian kolom dimodelkan seperti ditunjukkan pada Gambar 2. Pada penelitian kali ini $\mathrm{CO}_{2}$ sebagai adsorbat dan molecular sieve tipe 5A sebagai adsorben.

Proses adsorpsi pada kolom molecular sieve diasumsikan sebagai sebuah tabung dengan ketinggian $\mathrm{L}$, dan diameter $\mathrm{d}$, dengan zeolit di dalam tabung. Aliran gas pengotor masuk ke tabung dengan konsentrasi tertentu. Ada beberapa asumsi yang digunalan dalam simulasi menggunakan Matlab yaitu antara lain:

- Jumlah pengotor sangat kecil yaitu 40 ppmv sehingga pengurangan gas karena adsorpsi diabaikan, semua sifat gas helium yang digunakan sebagai acuan dasar perhitungan.
- $\mathrm{CO}_{2}$ sebagai adsorbat terserap dalam poripori molecular sieve

- Ukuran partikel adsorben (molecular sieve) kecil mempunyai komposisi yang seragam

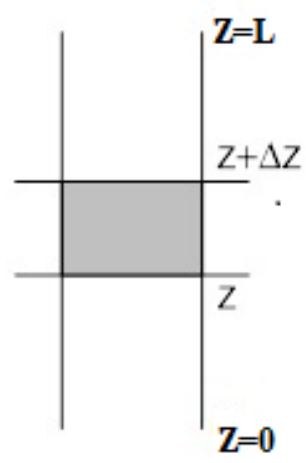

Gambar 2. Model kolom molecular sieve dengan perubahan ketinggian.

Secara umum, neraca massa adsorbat pada elemen volume gas dapat ditentukan menggunakan persamaan dasar bahwa : laju akumulasi = laju input - laju keluar - laju adsorpsi. Persamaan transfer massa adsorbat dari gas ke adsorben ditentukan dengan persamaan (12) [34], yaitu:

$F_{A}=k_{y} a \frac{\rho_{g}}{M r_{g}}\left(y_{A}-y_{A}^{*}\right) S \Delta z \varepsilon$

Dari persamaan (12) dapat dihitung keseimbangan padat-gas yang ditentukan dengan berbagai hukum keseimbangan yaitu hukum Henry (persamaan 13), Freundlich (persamaan 14), dan Langmuir (persamaan 15).

$y_{A}^{*}=H_{A} \cdot x_{A}$

$y_{A}^{*}=K_{f} \cdot x_{A}^{n_{f}}$

$y_{A}^{*}=\frac{a x_{A}}{1+b x_{A}}$

dengan: $F_{A}$ adalah konsentrasi adsorbat yang ditransfer per satuan waktu $(\mathrm{mol} / \mathrm{s}), k_{y}$ adalah koefisien transfer massa pada fase gas $\left(\mathrm{m}^{2} / \mathrm{s}\right)$, a adalah luas per satuan volume $\left(\mathrm{m}^{2} / \mathrm{m}^{3}\right), y_{A}$ adalah fraksi mol adsorbat pada gas, $y_{A} *$ adalah fraksi mol adsorbat di permukaan adsorben, $S$ adalah luas penampang kolom $\left(\mathrm{m}^{2}\right), \Delta z$ adalah pertambahan panjang $(\mathrm{m}), \mathcal{\varepsilon}$ adalah porositas kolom $(b e d), H_{A}$ adalah konstanta Henry, $K_{f}$ dan $n_{f}$ adalah konstanta kesetimbangan Freundlich, $A$ dan $b$ adalah konstanta kesetimbangan 
Langmuir, $X_{A}$ adalah fraksi mol adsorbat per massa adsorben.

Pengotor dapat didefinisikan diawal program. Diagram alir (flow chart) proses adsorpsi dengan PSA ditunjukkan pada Gambar 3, 4 dan 5. Diagram alir tersebut secara berturutan menjelaskan program utama, fungsi tekanan parsial dan fungsi propertis adsorbat.

Data-data properties pengotor yang harus dimasukkan (diinput) adalah berat molekul (BM). Metode adsorpsi yang menjadi pilihan adalah metode Henry. Metode adsorpsi linier Henry cocok digunakan untuk pengotor dengan konsentrasi yang sangat kecil dibandingkan medianya (fluida yang sangat encer) [35]. Program utama memanggil fungsi tekanan parsial, dan fungsi properties dari gas helium, dan pengotor $\mathrm{CO}_{2}$ kemudian menghitung proses adsorpsi sepanjang increment panjang, dan menampilkan hasil perhitungan berupa konsentrasi sisa $\mathrm{CO}_{2}$ dan ploting grafik yang dibutuhkan.

\section{HASIL DAN PEMBAHASAN}

Berdasarkan persyaratan desain, pengotor $\mathrm{CO}_{2}$ dalam pendingin primer harus dihilangkan sampai dengan batas maksimalnya yaitu < 0,6 ppmv. Dalam pendingin primer Peluit, gas $\mathrm{CO}_{2}$ terbentuk karena reaksi oksidasi karbon yaitu interaksi Oksigen dengan unsur Karbon di dalam teras. Selain $\mathrm{CO}_{2}$ (karbon dioksida) ada pengotor CO (karbon monoksida) yang harus dibersihkan dengan proses konversi terdahulu dari $\mathrm{CO}$ menjadi $\mathrm{CO}_{2}$ menggunakan oksidator $\mathrm{CuO}$. Oksidasi gas $\mathrm{H}_{2}$ dan $\mathrm{CO}$ menggunakan $\mathrm{CuO}$ mengubah $\mathrm{H}_{2}$ menjadi $\mathrm{H}_{2} \mathrm{O}$ sedangkan $\mathrm{CO}$ menjadi $\mathrm{CO}_{2}$. Kedua senyawa ini akan lebih mudah dipisahkan dibandingkan dalam bentuk $\mathrm{H}_{2}$ dan $\mathrm{CO}$ karena mempunyai ukuran molekul yang lebih besar. $\mathrm{H}_{2} \mathrm{O}$ dipisahkan dari gas helium dengan proses kondensasi sedangkan $\mathrm{CO}_{2}$ dipisahkan dengan adsorpsi molekuler/molecular sieve. Proses kondensasi akan menghasilkan air dan akan diolah sebagai limbah cair, sedangkan $\mathrm{CO}_{2}$ yang terserap dalam matriks zeolit akan diregenerasi dan gas $\mathrm{CO}_{2}$ akan diolah sebagai limbah gas. Struktur molekul zeolit 5A adalah $\mathrm{Na}_{12}\left[\left(\mathrm{AlO}_{2}\right) 12\left(\mathrm{SiO}_{2}\right)_{12}\right] .27 \mathrm{H}_{2} \mathrm{O}$ dengan kapasitas adsorpsi terhadap $\mathrm{CO}_{2}$ pada rentang temperatur
100-200 ${ }^{\circ} \mathrm{C}$ adalah adalah 0,056 - 1,033 $\mathrm{mmol} / \mathrm{g}$ [36].

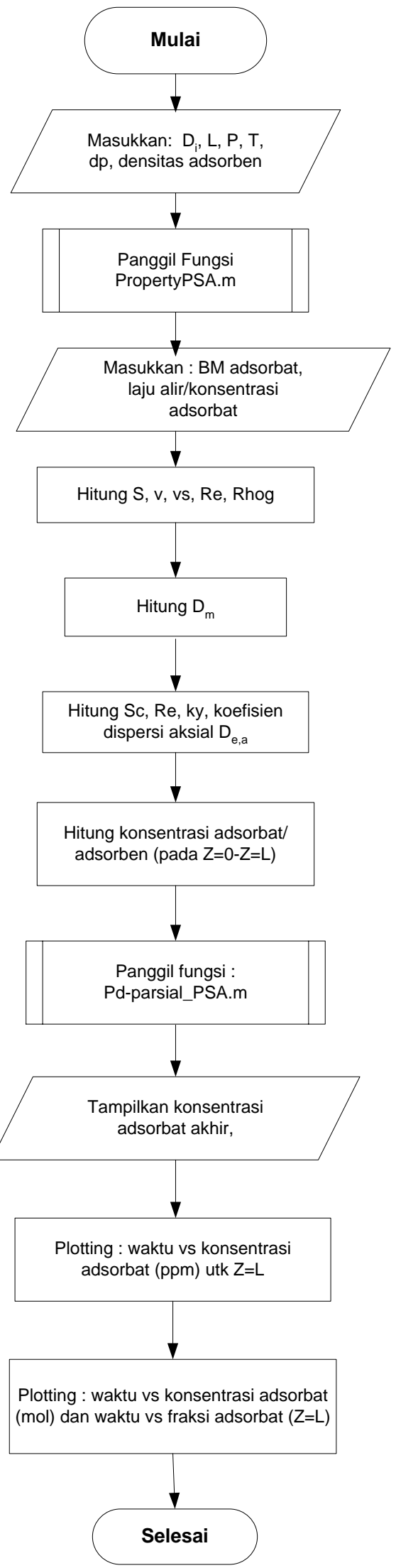

Gambar 3. Diagram Alir Program Utama Perhitungan Adsorpsi pada Molecular Sieve Metode PSA dengan Matlab. 


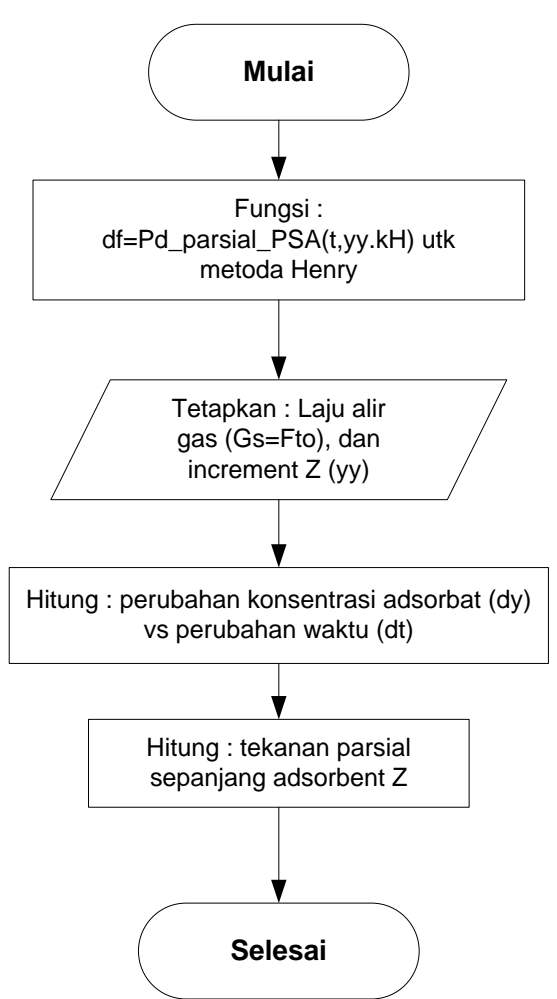

Gambar 4. Diagram Alir Fungsi Perhitungan Tekanan Parsial Metode PSA dengan Matlab.

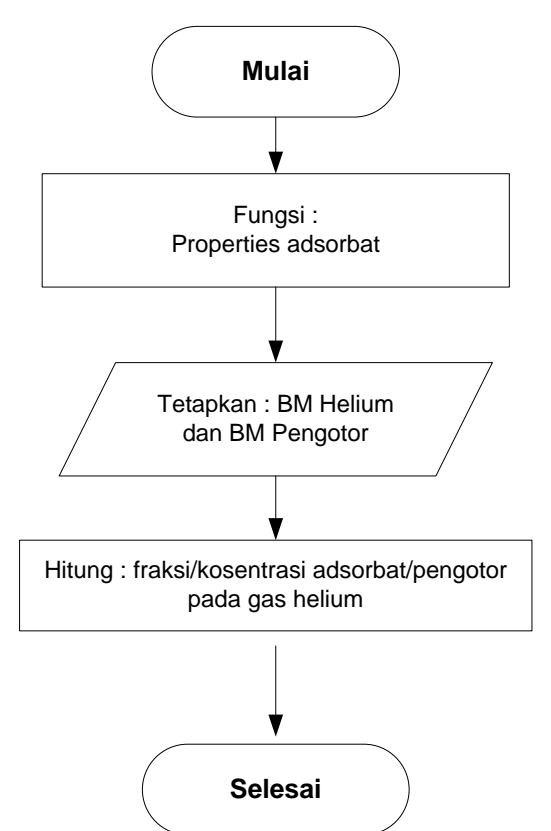

Gambar 5. Diagram Alir Fungsi Perhitungan Parameter/Properties Adsorbat pada molecular sieve dengan Matlab.

Pada sisi masukan kolom, konsentrasi awal $\mathrm{CO}_{2}$ ditentukan 40 ppmv. Metode adsorpsi yang disimulasikan adalah metode Henry karena konsentrasi pengotor sangat kecil dibandingkan fluida heliumnya. Ketinggian kolom diasumsikan dengan $\mathrm{L}=200 \mathrm{~cm}$, dan diameter bed/kolom molecular sieve adalah 50 $\mathrm{cm}$. dengan konsentrasi pengotor $\mathrm{CO}_{2}$ awal adalah 40 ppmv. Konsentrasi ini nilainya jauh melebihi dari batas maksimum 0,6 ppmv dalam pendingin primer, yaitu 60 kalinya.

Pada simulasi diamati, konsentrasi pengotor/adsorbat pada tiga titik area ketinggian kolom yaitu ketinggian $\mathrm{L}=50 \mathrm{~cm}$ (seperempat panjang kolom), $\mathrm{L}=100 \mathrm{~cm}$ (setengah panjang kolom) dan $\mathrm{L}=200 \mathrm{~cm}$ (satu kolom penuh). Gambar 6 menunjukkan hubungan antara waktu dan konsentrasi pengotor $\mathrm{CO}_{2}$ yang terdeteksi (tersisa) pada aliran gas helium di ketinggian kolom $50 \mathrm{~cm}$, $100 \mathrm{~cm}$ dan $200 \mathrm{~cm}$.

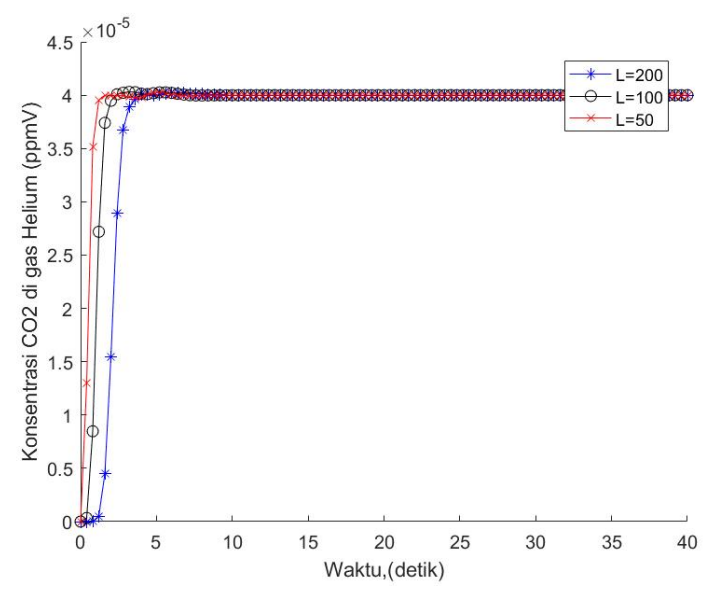

Gambar 6. Hubungan konsentrasi CO2 di gas helium dengan waktu pada ketinggian kolom molecular sieve.

Berdasarkan Gambar 6 pula dapat dijelaskan bahwa titik $\mathrm{L}=0 \mathrm{~cm}$, adalah titik awal input gas helium kotor yang masuk ke kolom molecular sieve. Pada ketinggian $\mathrm{L}=50 \mathrm{~cm}$, konsentrasi pengotor mulai terdeteksi pada 0,5 detik pertama dan kemudian konsentrasi pengotor selalu tetap pada $4 \times 10^{-5}$ ppmv pada detik ke 2. Hal ini menunjukkan bahwa pada detik ke 2, pada ketinggian $50 \mathrm{~cm}$, konsentrasi pengotor tersisa pada gas helium adalah $4 \times 10^{-}$ ${ }^{5}$ ppmv, sedangkan sebanyak 39,99996 ppmv atau 99,99\% terserap di dalam adsorben zeolit di sepanjang $\mathrm{L}=0-50 \mathrm{~cm}$.

Pada titik pengamatan $\mathrm{L}=100 \mathrm{~cm}$, diketahui bahwa konsentrasi pengotor $\mathrm{CO}_{2}$ keluar pada ujung $\mathrm{L}=100 \mathrm{~cm}$ mulai terdeteksi pada $t=2,5$ detik, dan akan mencapai kestabilan pada $\mathrm{t}=4,5$ detik dengan konsentrasi pengotor tersisa $4 \times 10^{-5}$ ppmv.

Pada titik pengamatan $\mathrm{L}=200 \mathrm{~cm}$, diketahui bahwa konsentrasi pengotor $\mathrm{CO}_{2}$ 
keluar pada ujung $\mathrm{L}=200 \mathrm{~cm}$ mulai terdeteksi pada $\mathrm{t}=5$ detik, dan akan mencapai kestabilan pada $\mathrm{t}=8,5$ detik dengan konsentrasi pengotor tersisa $4 \times 10^{-5}$ ppmv. Konsentrasi sisa pengotor pada titik-titik tersebut akan mengalami peningkatan setelah durasi waktu tertentu, hal ini dikarenakan adsorben/zeolit mengalami kejenuhan sehingga pengotor $\mathrm{CO}_{2}$ tidak mampu diserap lagi. Jika hal ini terjadi maka perlu dilakukan proses regenerasi terhadap zeolit, dengan menaikkan temperatur proses/pemanasan sehingga $\mathrm{CO}_{2}$ akan terlepas dan matriks zeolit menjadi bersih kembali untuk siap digunakan sebagai adsorben.

Hasil simulasi jumlah $\mathrm{CO}_{2}$ terserap pada matriks molecular sieve ditunjukkan pada Gambar 7. Jumlah adsorbat $\left(\mathrm{CO}_{2}\right)$ yang terserap pada adsorben (molecular sieve tipe 5A) pada mencapai konsentrasi yang tetap yaitu $1 \times 10^{-4}$ ppmv menunjukkan pada capaian waktu yang berbeda karena proses penyerapan $\mathrm{CO}_{2}$ ke matriks molecular sieve membutuhkan waktu kontak tertentu. Pada ketinggian $\mathrm{L}=50 \mathrm{~cm}$ mencapai jumlah konsentrasi tetap tersebut dicapai pada 1,5 detik, untuk $\mathrm{L}=100 \mathrm{~cm}$ pada 2 detik, sedangkan pada $\mathrm{L}=200 \mathrm{~cm}$ tercapai pada 3,5 detik. Konsentrasi tetap tercapai pada waktu yang pendek disebabkan karena konsentrasi pengotor diasumsikan sangat kecil berdasarkan pengalaman operasi HTGR [16].

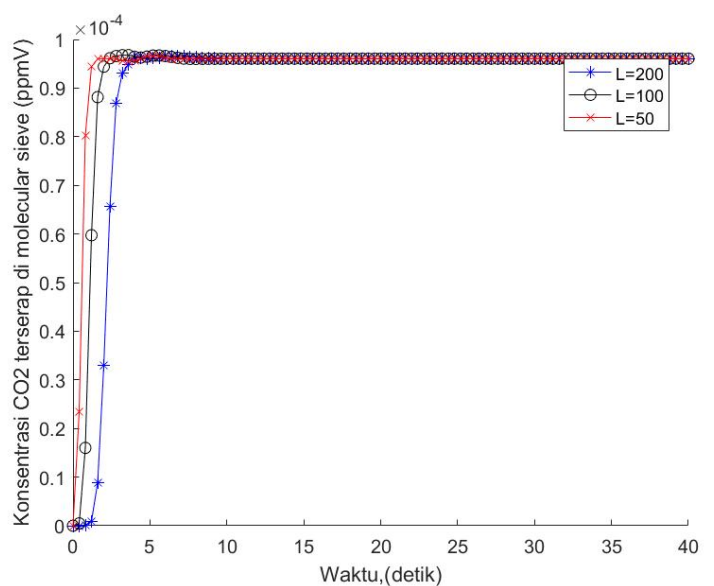

Gambar 7. Hubungan konsentrasi $\mathrm{CO}_{2}$ terserap dengan waktu pada ketinggian kolom molecular sieve.

Hasil simulasi jumlah fraksi adsorbat di dalam gas helium ditunjukkan pada Gambar 8, dalam simulasi menunjukkan bahwa fraksi adsorbat $4 \times 10^{-5}$ ppmv pada kesetimbangan konsentrasi setelah proses 5 detik.

Gambar 9 menjelaskan hasil simulasi jumlah mol adsorbat terserap dalam matriks molecular sieve selama perubahan waktu $\mathrm{t}_{1}=1$ detik, $t_{2}=3$ detik, $t_{3}=5$ detik, $t_{4}=10$ detik dan $\mathrm{t}_{5}=15$ detik di variasi panjang kolom. Jumlah adsorbat terserap pada matriks molecular sieve adalah ditunjukkan sebagai luasan area dibawah masing masing garis grafik yang terbentuk.

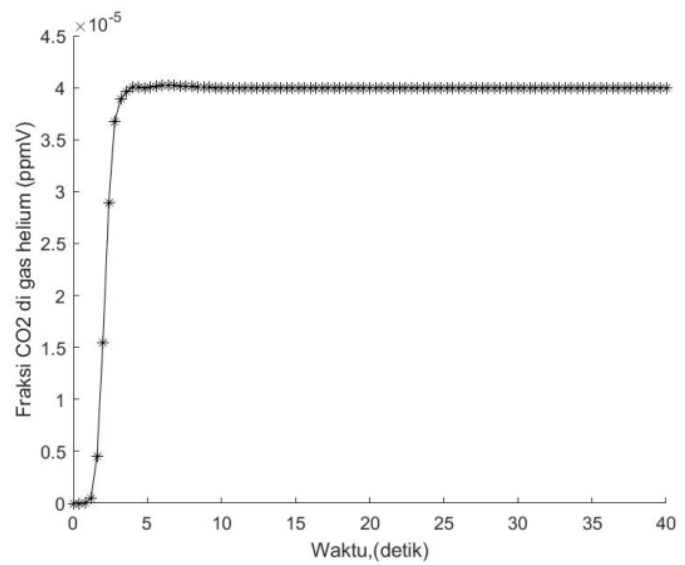

Gambar 8. Hubungan pengotor $\mathrm{CO}_{2}$ terdeteksi pada ujung kolom dengan waktu.

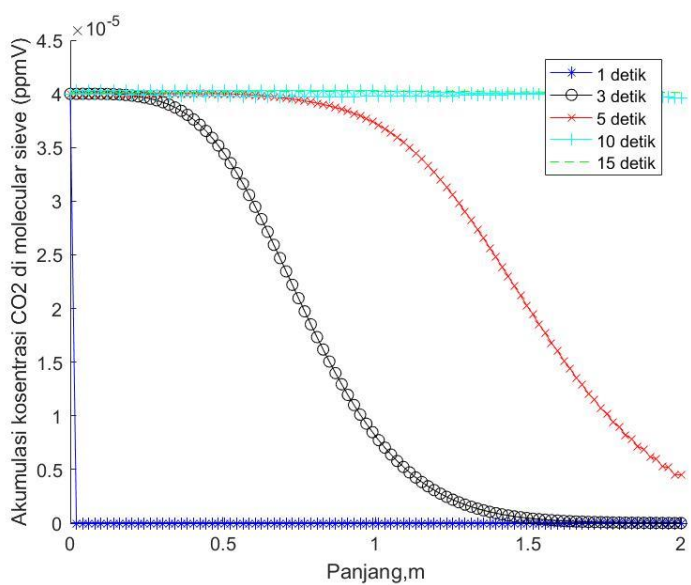

Gambar 9. Akumulasi $\mathrm{CO}_{2}$ terserap terhadap ketinggian pada kolom molecular sieve.

Proses penyerapan $\mathrm{CO}_{2}$ pada molecular sieve sangat tergantung dengan waktu kontak antara adsorbat (pengotor) dengan matriks molecular sieve. Semakin lama waktu kontak gas helium yang akan dibersihkan dengan material molecular sieve maka akan semakin baik proses pemurniannya. Hal ini dapat ditunjukkan pada Tabel 4, dengan memvariasikan ketinggian kolom molecular sieve maka didapatkan kemurnian helium yang semakin tinggi pula. Tabel 4 menunjukkan hubungan ketinggian kolom (L) dan konsentrasi $\mathrm{CO}_{2}$ tersisa pada aliran ujung kolom molecular sieve. Dengan menggunakan spesifikasi teknis disain kolom molecular sieve yang sama baik 
itu konsentrasi input pengotor, temperatur, tekanan, dan diameter tetapi ketinggian kolom (L) divariasikan dari 2,0 m, sampai 7,0 m maka didapatkan sisa adosrbat pada ujung kolom yang semakin kecil. Hal ini membuktikan bahwa waktu kontak adsorbat (gas helium kotor) dengan adsorben (molecular sieve 5A) sangat menentukan efisiensi pemisahannya.

Tabel 4. Hubungan tinggi kolom dengan konsentrasi $\mathrm{CO}_{2}$ tersisa pada ujung kolom molecular sieve.

\begin{tabular}{|c|c|c|}
\hline $\begin{array}{l}\text { Ketinggian } \\
\text { kolom (m) }\end{array}$ & $\begin{array}{l}\text { Konsentrasi } \mathrm{CO}_{2} \\
\text { pada input } \mathrm{L}=0 \\
\text { (ppmv) }\end{array}$ & $\begin{array}{l}\text { Konsentrasi } \mathrm{CO}_{2} \\
\text { tersisa pada ujung } \\
\text { kolom } \mathrm{Z}=\mathrm{L} \text { (ppmv) }\end{array}$ \\
\hline 2,00 & 40 & $4,0000 \times 10^{-5}$ \\
\hline 3,00 & 40 & $4,0000 \times 10^{-5}$ \\
\hline 4,00 & 40 & $4,0000 \times 10^{-5}$ \\
\hline 5,00 & 40 & $3.9999 \times 10^{-5}$ \\
\hline 6,00 & 40 & $3.9996 \times 10^{-5}$ \\
\hline 7,00 & 40 & $3.9994 \times 10^{-5}$ \\
\hline
\end{tabular}

\section{KESIMPULAN}

Proses adsorpsi pada molecular sieve telah disimulasikan dengan software Matlab. Tinggi kolom diasumsikan $200 \mathrm{~cm}$, diameter kolom $50 \mathrm{~cm}$, laju aliran gas helium adalah $5 \%$ dari aliran utama pendingin primer setara dengan $3,0 \mathrm{~kg} / \mathrm{s}$, dan konsentrasi pengotor $\mathrm{CO}_{2}$ adalah 40 ppmv. Berdasarkan simulasi diketahui bahwa setelah 5 detik, gas helium bersih sudah keluar dari ujung kolom dengan konsentrasi pengotor $\mathrm{CO}_{2}$ tersisa $4 \times 10^{-5}$ ppmv. Dengan hasil ini menunjukkan bahwa kolom molecular sieve mampu membersihkan pengotor $\mathrm{CO}_{2}$ dengan efisiensi 99,99\%. Penelitian penyerapan pengotor $\mathrm{CO}_{2}$ menggunakan molecular sieve 5A ini berhasil membuktikan bahwa sisa pengotor pada gas helium memenuhi syarat batas maksimum yang diijinkan dalam pendingin primer reaktor Peluit.

\section{UCAPAN TERIMA KASIH}

Penulis mengucapkan banyak terima kasih kepada Pusat Teknologi dan Keselamatan Reaktor Nuklir (PTKRN)-Batan atas dukungan fasilitas laboratorium dan perangkat lunak yang diberikan.

\section{DAFTAR ACUAN}

[1] BPPT, Outlook Energi Indonesia 2017. 2017.

[2] T. Setiadipura, J. S. Pane, and Z. Basjemeleh, "Studi Awal Desain Pebble Bed Reactor Berbasis HTR-PM Dengan Resirkulasi Bahan Bakar OnceThrough-Then-Out," J. Pengemb. Energi Nukl., vol. 18, no. 1, pp. 59-65, 2016.

[3] Sriyono Sriyono, R. Kusmastuti, S. Bakhri, and G. R. Sunaryo, "Analysis of helium purification system capability during water ingress accident in RDE," J. Phys. Conf. Ser., vol. 962, no. 1, 2018.

[4] D. H. Salimy et al., "The assessment of nuclear hydrogen cogeneration system application for steel industry," AIP Conf. Proc., vol. 2180, no. December, 2019.

[5] S. Sriyono, R. Kusumastuti, A. Hafid, and D. H. Salimy, "Temperature profile analysis on cryogenic activated carbon column of helium purification testing facility," AIP Conf. Proc. 2180, 020046, vol. 020046, no. December, 2019.

[6] X. Yu and S. Yu, "Analysis of fuel element matrix graphite corrosion in HTR-PM for normal operating conditions," Nucl. Eng. Des., vol. 240, no. 4, pp. 738-743, 2010.

[7] S. Sriyono, I. Karliana, S. Sumijanto, and R. Kusumastuti, "Analisis Pressure Swing Asorption Pada Proses Penyerapan Gas Pengotor Oleh Molecualr sieve Pada Sistem Pemurnian Helium RGTT200K," in Semnas TKPFN-19, 2013, pp. 200-209.

[8] W. Peng, T. Zhang, Y. Zhen, and S. Yu, "Graphite dust resuspension in an HTR-10 steam generator," Particuology, vol. 17, pp. 149-157, 2014.

[9] S. Sriyono, T. Setiadipura, and G. R. Sunaryo, "Carbon dust in primary coolant of RDE: its problem and solution," Tri Dasa Mega, vol. 22, no. 3, 2018.

[10] S. Sriyono et al., "The Temperature Dependence Analysis of Carbon Monoxide Conversion on $\mathrm{CuO}$ Bed of RDE Helium Purification System," J. Phys. Conf. Ser., vol. 1493, no. 1, 2020.

[11] D. Priambodo, M. Pancoko, Sriyono, and T. Setiadipura, "Design of Helium Purification System for Indonesia Experimental Power ReactorReaktor Daya Eksperimental," Int. J. Mech. Eng. Technol., vol. 6, no. 7, pp. 1-7, 2018.

[12] R. NIEDER, "Predictions on an HTR Coolant Composition after Operational Experience With Experimental Reactors," in Specialists Meeting on Coolant Chemistry, Plate-out and Decontamination in Gas-cooled Reactors, 1980, pp. 144-152.

[13] S. Sumijanto, N. Huda, and S. Sriyono, "Optimasi Laju Konversi Molekuler CO Pada Sistem Pemurnian Helium RGTT200K," Pros. Semin. Nas. Teknol. Energi Nukl., 2015.

[14] J. J. van der Merwe and P. P. Coetzee, "Development of a model to predict fission product behaviour in spherical fuel elements during water ingress events," Nucl. Eng. Des., vol. 237, no. 1, pp. 47-53, 2007.

[15] S. Sriyono et al., "Temperature profile analysis on cryogenic activated carbon column of helium purification testing facility," AIP Conf. Proc., vol. 2180, no. December, 2019.

[16] K. Natesan, A. Purohit, and S. W. Tam, "Materials 
Behavior in HTGR Environments," NUREG/CR6824, p. 85, 2003.

[17] I. Mutoh, Y. Nakasone, K. Hiraga, and T. Tanabe, "Corrosion behavior of $\mathrm{Ni}$-base superalloys at $1373 \mathrm{~K}$ in simulated HTGR impure helium gas environment," J. Nucl. Mater., vol. 207, no. C, pp. 212-220, 1993

[18] Sriyono, R. Kusmastuti, S. Bakhri, and G. R. Sunaryo, "Analysis of helium purification system capability during water ingress accident in RDE," in Journal of Physics: Conference Series, 2018, vol. 962, no. 1.

[19] P. Sinha and N. Padhiyar, "Optimal startup operation of a pressure swing adsorption," IFACPapersOnLine, vol. 52, no. 1, pp. 130-135, 2019.

[20] I. D. Irianto, Sriyono, S. Bakhri, S. Dibyo, R. Kusumastuti, and P. Kadarno, "Performance Analysis of the Helium Purification System in the Indonesia Experimental Power Reactor," J. Phys. Conf. Ser., vol. 1772, no. 1, 2021.

[21] Y. Zheng, L. Shi, and Y. Wang, "Water-ingress analysis for the 200 MWe pebble-bed modular high temperature gas-cooled reactor," Nucl. Eng. Des., vol. 240, no. 10, pp. 3095-3107, 2010.

[22] Y. Wang, L. Shi, and Y. Zheng, "Influence of protective actions on ingress-water mass in Steam generator tube rupture of HTGR," in International Topical Meeting on High Temperature Reactor Technology, HTR 2016, 2016, pp. 439-445.

[23] R. C. Martineau and R. A. Berry, "A preliminary investigation of rapid depressurization phenomena following a sudden DLOFC in a VHTR," Nucl. Eng. Des., vol. 240, no. 5, pp. 1013-1021, 2010.

[24] G. Zuying and S. Lei, "Thermal hydraulic transient analysis of the HTR-10," Nucl. Eng. Des., vol. 218, no. 1-3, pp. 65-80, 2002.

[25] A. Kurniawan, "Pengukuran Parameter Kualitas Udara (CO, NO2, SO2, O3 dan PM10) Di Bukit Kototabang Berbasis Ispu," J. Teknosains, vol. 7, no. 1, p. $1,2018$.

[26] D. Priambodo, M. Pancoko, and T. Setiadipura, "Design of Helium Purification System for Indonesia Experimental Power Reactor- Reaktor Daya Eksperimental," vol. 6, no. 7, pp. 1-7, 2018.

[27] Z. Wu, D. Lin, and D. Zhong, "The design features of the HTR-10," Nucl. Eng. Des., vol. 218, no. 1-3, pp. 25-32, 2002.

[28] S. Sriyono, A. M. Hilda, and M. Kamayani, "Pemodelan dan Simulasi Proses Adsorpsi Gas Pengotor oleh Molecular Sieve pada Pendingin Rde dengan Software Chemcad," Pros. Semin. Nas. Teknoka, 2019

[29] R. V Siriwardane, M.-S. Shen, E. P. Fisher, and J. A. Poston, "Adsorption of CO2 on Molecular Sieves and Activated Carbon," Energy \& Fuels, vol. 15, no. 2, pp. 279-284, Mar. 2001.

[30] A. Wahby, J. Silvestre-Albero, A. SepúlvedaEscribano, and F. Rodríguez-Reinoso, "CO2 adsorption on carbon molecular sieves," Microporous Mesoporous Mater., vol. 164, pp. 280-287, 2012.
[31] M. S. Yao, R. P. Wang, Z. Y. Liu, X. D. He, and J. Li, "The helium purification system of the HTR-10," Nucl. Eng. Des., vol. 218, no. 1-3, pp. 163-167, 2002

[32] L. M. Mulloth, "Carbon Dioxide Adsorption in Spacecraft on a 5A Zeolite Cabins Designed for CO 2 Removal," no. November, 1998.

[33] C. Hua, W. Zong-xin, Y. Mei-sheng, and G. Shi-yi, "Experimental Investigation and Modeling of Adsorption of Carbon Dioxide on 5A Molecular Sieve for Helium Purification of High-Temperature Gas-cooled Reactor," Energy Procedia, vol. 39, pp. 208-226, 2013.

[34] D. W. Green and R. H. Perry, Perry's Chemical Engineers Handbook, 8th ed. Mc. Graw-Hill, 2008.

[35] J. B. Utami, W. B. Sediawan, B. Murachman, and G. S. Wijaya, "Prediksi Kesetimbangan Adsorpsi Uranium pada Air dan berbagai sedimen," J. Forum Nukl., vol. 9, no. 2, pp. 29-37, 2015.

[36] C. Megías-Sayago, R. Bingre, L. Huang, G. Lutzweiler, Q. Wang, and B. Louis, "CO2 Adsorption Capacities in Zeolites and Layered Double Hydroxide Materials," Front. Chem., vol. 7, 2019 